\title{
Meta-analysis of the therapeutic effects of antibiotic versus appendicectomy for the treatment of acute appendicitis
}

\author{
ZHI-HUA LIU, CHAO LI, XING-WEI ZHANG, LIANG KANG and JIAN-PING WANG \\ Department of Colorectal Surgery, The Sixth Affiliated Hospital to Sun Yat-Sen University, \\ Guangzhou, Guangdong 510655, P.R. China
}

Received September 6, 2013; Accepted January 22, 2014

DOI: $10.3892 /$ etm.2014.1584

\begin{abstract}
Appendicectomy has been the gold standard treatment of acute appendicitis for more than a century, while nonoperative therapies, including antibiotics, have acquired increased interest in recent years. The present meta-analysis aimed to compare the therapeutic effects of antibiotics versus appendicectomy for the treatment of acute appendicitis. Medline, Embase and The Cochrane Library databases were searched. Prospective randomized controlled trials that compared antibiotic treatment with surgery were included. The outcomes evaluated included the time of hospital stay, complications and time to work. There were no statistically significant differences between the antibiotic and appendicectomy groups with regard to the time of hospital stay and complications. However, the time to work was significantly longer in the appendicectomy group when compared with the antibiotic group. In addition, the therapeutic effects of antibiotics and appendicectomy were comparable for the treatment of acute appendicitis.
\end{abstract}

\section{Introduction}

Acute appendicitis is the most common etiology of acute abdomen (1). Appendicectomy has been the predominant treatment of acute appendicitis for more than a century since being introduced by McBurney in the 1880's and being performed by Grooves in 1883 . Since then, the procedure has been standardized among surgeons (2). In 1886, Fitz published a classic study of 247 patients with perforated appendicitis, whereby early appendectomy was advocated (3). As a classic surgical procedure, open appendicectomy is considered to be safe and effective surgery for acute appendicitis that avoids perforation. It is the gold standard treatment of appendicitis

Correspondence to: Dr Jian-Ping Wang, Department of Colorectal Surgery, The Sixth Affiliated Hospital to Sun Yat-Sen University, No. 26 Yuancun Erheng Road Guangzhou, Guangdong 510655, P.R. China

E-mail: jianpingwangcn@163.com

Key words: meta-analysis, acute appendicitis, antibiotic, nonoperative, appendicectomy due to low morbidity, short length of hospitalization and rare postoperative complications. Prompt appendicectomy is traditionally used for treating acute appendicitis, with the exception of immediate appendicectomy, which may be technically demanding due to the distorted anatomy and difficulties in closing the appendiceal stump as a result of inflamed tissues (4). Exploratory laparotomy often results in an ileocecal resection or a right-sided hemicolectomy due to technical problems or a suspicion of malignancy resulting from the presence of distorted tissues (5).

Nonoperative management has been used for a number of patients. In 1959, Coldrey reported 471 patients who underwent treatment with antibiotics alone and in 1977 , Anonymous reported 425 patients who were treated with antibiotics and traditional Chinese medicine (6,7). Previously, nonoperative treatment has played a minor role in treating acute appendicitis. However, it may be used to avoid surgical complications, including small bowel obstruction and negative appendicectomy. Recently, with the development of imaging diagnosis, including computerized tomography and ultrasound, nonoperative therapy for the treatment of acute appendicitis has acquired increasing interest. Investigations into novel and efficient antibiotics have also provided new opportunities for nonsurgical treatment of appendicitis (8). Antibiotic therapy, the main nonoperative therapy, is becoming increasingly important in the treatment of acute appendicitis $(9,10)$. Previous studies have shown that perforated appendicitis in children may be treated with antibiotics (11-13). Furthermore, retrospective studies in adults with perforated appendicitis who were treated conservatively indicated that late recurrences exhibited a mild clinical course (14). However, morbidity and mortality rates remained unsatisfactory for conservatively treated and appendectomized patients.

Randomized controlled trials (RCTs) have been conducted, however, the benefits of appendicectomy versus antibiotic treatment for appendicitis remain in debate. Specific studies have suggested that the surgical approach demonstrates a number of advantages, while other studies have been unable to conclusively identify a significant difference between the two treatments $(15,16)$. Therefore, the aim of the present meta-analysis was to compare antibiotic and appendicectomy treatment for acute appendicitis in cases where surgeons were not limited by technical constraints. 


\section{Materials and methods}

Search strategy. Objectives, search strategy, study selection criteria, data elements, methods for extraction and methods for assessing study quality were defined. Four independent reviewers completed each step in this protocol and resolved disagreements by discussion.

Literature search. To identify all the relevant studies, a computerized search (Medline, http://www.ncbi.nlm.nih.gov/ pubmed; Embase, http://www.embase.com/info/helpfiles/; and The Cochrane Library, http://www.thecochranelibrary.com/) was performed using the terms 'antibiotic', 'appendicectomy', 'acute appendicitis', 'versus' and 'conservative' (Fig. 1). In addition, the reference lists in selected articles were searched manually. There was no language restriction and the time frame was between June 1996 and September 2012. Relevant RCTs were identified that compared antibiotics with surgery for the treatment of acute appendicitis in cases where surgeons were not limited by technical constraints. All patient groups were well matched in terms of subjects and clinical and diagnostic variables at inclusion. Appendicectomy was performed openly or laparoscopically at the surgeon's discretion. Whenever possible, surgery was performed by a training registrar with an experienced surgeon supervising the operation. Patients in the antibiotic group received intravenous antibiotics for at least $24 \mathrm{~h}$ and those whose clinical status had improved the following day were discharged to continue with oral antibiotics for $\sim 10$ days. In patients whose clinical conditions showed no improvement, intravenous treatment was prolonged.

Study selection. Citations selected from the initial search were subsequently screened for eligibility. Diagnosis of appendicitis, determined by the attending physician, was made on the following criteria: History of right lower quadrant pain or periumbilical pain migrating to the right lower quadrant with nausea or vomiting; fever of $>38^{\circ} \mathrm{C}$ or leukocytosis of $>10,000$ cells $/ \mathrm{ml}$; right lower quadrant guarding and tenderness on physical examination; and in certain cases, ultrasonography, computed tomography and gynecological examination. Patients were included in the study if they were aged $\geq 9$ years and were part of a RCT that compared antibiotic treatment with surgery in acute appendicitis. Patients were excluded if they were $<9$ years old, pregnant, had a history of drug abuse and/or psychiatric disorders and were not involved in a RCTs.

Data extraction. Data were extracted independently by two reviewers (Liu Zhihua and Qin Huanlong) and cross-checked to reach a consensus. The following variables were recorded: Author, journal, date of publication, geographical region, number of patients, age, gender, body temperature, white blood cell count on admission, C-reactive protein, time of hospital stay, complications and time to work. If necessary, the primary authors were contacted to retrieve further information.

Statistical analysis. Dichotomous variables were analyzed with odds ratios (ORs) and a fixed-effects model was used according to heterogeneity. Continuous variables, when the mean and SD were presented, were assessed using the weighted mean difference (WMD) and a random-effects model was

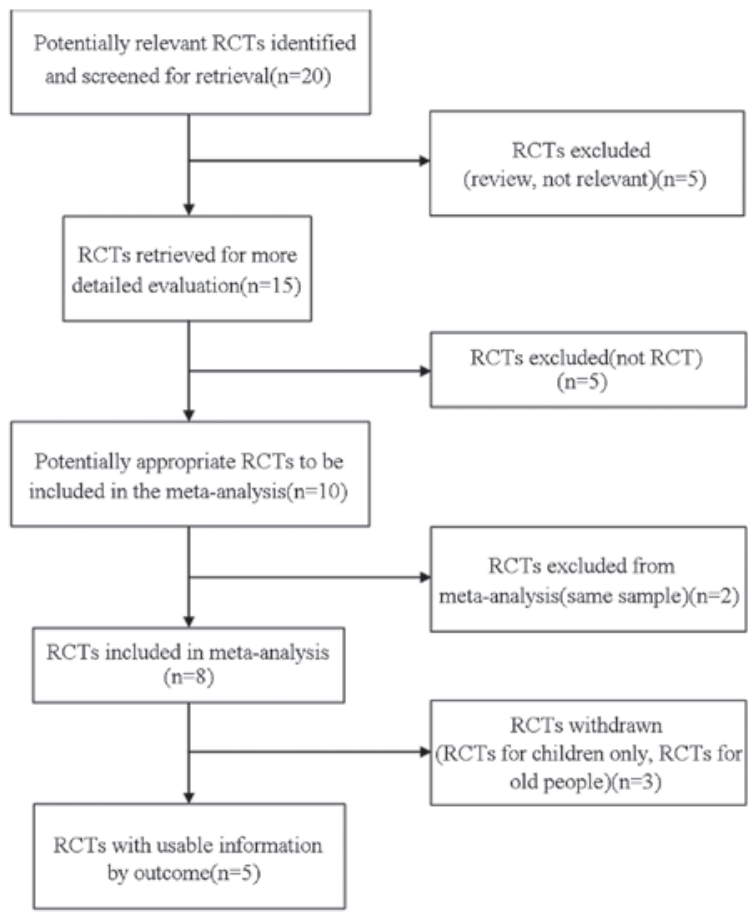

Figure 1. Quality of reporting meta-analyses diagram showing the study methodology. RCT, randomized controlled trial.

used according to heterogeneity if significant heterogeneity was present. Sensitivity analysis was applied by removing individual studies from the data set and analyzing the effects on the overall results to identify sources of significant heterogeneity (17). Data analyses were performed using Review Manager version 4.2 software (Nordic Cochrane Centre, Copenhagen, Denmark). $\mathrm{P}<0.05$ was considered to indicate a statistically significant difference.

Assessment of study quality. Included trials were reviewed and appraised for methodological quality using the Jadad composite scale (17). High-quality trials scored $>2$ out of a maximum possible score of 5 (18).

\section{Results}

Description of studies. Of the 983 patients in the five RCTs (19-23), 391 patients were allocated to the antibiotic group, while 592 patients comprised the appendicectomy group. The therapeutic effects of each treatment were evaluated. Patient characteristics and evaluation index are shown in Tables I and II, respectively.

Methodological quality. The mean Jadad score of the included studies was 3 out of a maximum possible score of 5 (Table III). The main study limitation was associated with the limited sample numbers in three of the studies. However, the sample size of the meta-analysis included 983 patients. Therefore, the limitation may not have an important effect.

Outcome of comparison. Meta-analysis revealed that the time of hospital stay (days) in the five studies (19-23) was not significantly different in the antibiotic group when compared with 
Table I. Patient characteristics comparing antibiotic treatment with appendicectomy in acute appendicitis.

Antibiotic treatment/Appendicectomy

\begin{tabular}{|c|c|c|c|c|c|}
\hline \multirow[b]{2}{*}{ Characteristics } & \\
\hline & Gibeily GJ (14) & Hansson J (15) & Styrud J (16) & Turhan AN (17) & Eriksson S (18) \\
\hline Patients, $\mathrm{n}$ & $17 / 15$ & $119 / 250$ & $128 / 124$ & $107 / 183$ & $20 / 20$ \\
\hline Age, years & 38.3 & $37 / 34$ & NR & NR & $27.8 / 35.0$ \\
\hline Males, $\mathrm{n}$ & $40.95 / 8$ & $62 / 138$ & $128 / 124$ & $65 / 125$ & $14 / 13$ \\
\hline Females, $\mathrm{n}$ & $12 / 7$ & $57 / 112$ & $0 / 0$ & $42 / 58$ & $6 / 7$ \\
\hline Body temperature, ${ }^{\circ} \mathrm{C}$ & NR & $37.5 / 37.5$ & $37.5 / 37.4$ & NR & $37.2 / 37.1$ \\
\hline $\mathrm{WBC}, \mathrm{k} / \mathrm{mm}^{3}$ & $12.1 / 14.3$ & $12.2 / 13.5$ & $12.5 / 12.4$ & NR & $13.8 / 13.9$ \\
\hline C-reactive protein, $\mathrm{mg} / \mathrm{l}$ & NR & $56 / 54$ & $55 / 54$ & NR & $41 / 40$ \\
\hline
\end{tabular}

WBC, white blood cell count; NR, not reported.

Table II. Evaluation index comparing antibiotic treatment with appendicectomy in acute appendicitis.

Antibiotic treatment/Appendicectomy

\begin{tabular}{lccccc}
\cline { 2 - 5 } Index & Gibeily GJ (14) & Hansson J (15) & Styrud J (16) & Turhan AN (17) & Eriksson S (18) \\
\hline Patients, $\mathrm{n}$ & $17 / 15$ & $119 / 250$ & $128 / 124$ & $107 / 183$ & $20 / 20$ \\
Hospital stay, days ${ }^{\mathrm{a}}$ & $8.6 \pm 1.7 / 7.8 \pm 0.9$ & $2+0.1 / 3+0.2$ & $3.0 \pm 1.4 / 2.6 \pm 1.2$ & $3.14 \pm 0.1 / 2.4 \pm 0.14$ & $3.1 \pm 0.1 / 3.4 \pm 1.9$ \\
Complications, $\mathrm{n}$ & $4 / 5$ & $36 / 80$ & $15 / 17$ & $\mathrm{NR}$ & $0 / 1$ \\
Time to work, days $^{\mathrm{a}}$ & $16.8 \pm 3.5 / 42 \pm 9.1$ & $\mathrm{NR}$ & $8.0 \pm 80 / 10.1 \pm 7.6$ & NR & NR
\end{tabular}

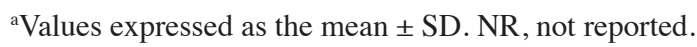

Table III. Jadad scores.

\begin{tabular}{|c|c|c|c|c|c|}
\hline \multirow[b]{2}{*}{ Methodological qualities } & \multicolumn{5}{|c|}{ Antibiotic treatment/Appendicectomy } \\
\hline & $\begin{array}{l}\text { Gibeily GJ } \\
\text { (14) }\end{array}$ & $\begin{array}{l}\text { Hansson } \mathrm{J} \\
\quad(15)\end{array}$ & $\begin{array}{l}\text { Styrud J } \\
\quad(16)\end{array}$ & $\begin{array}{l}\text { Turhan AN } \\
\text { (17) }\end{array}$ & $\begin{array}{l}\text { Eriksson S } \\
\quad(18)\end{array}$ \\
\hline Was the study described as randomized? & 1 & 1 & 1 & 1 & 1 \\
\hline $\begin{array}{l}\text { Was the method used to generate the sequence } \\
\text { of randomization described and appropriate? }\end{array}$ & 0 & 1 & 0 & 0 & 1 \\
\hline Was the study described as double-blind? & 0 & 1 & 0 & 0 & 1 \\
\hline $\begin{array}{l}\text { Was the method of double-blinding } \\
\text { described and appropriate? }\end{array}$ & 0 & 1 & 0 & 0 & 1 \\
\hline $\begin{array}{l}\text { Was there a description of withdrawals } \\
\text { and dropouts? }\end{array}$ & 1 & 1 & 1 & 1 & 1 \\
\hline Total & 2 & 5 & 2 & 2 & 5 \\
\hline
\end{tabular}

Yes, 1 ; no, 0 ; unknown, 0 . High-quality trials scored $>2$ out of a maximum possible score of 5 .

the appendicectomy group. In addition, there was no evidence of significant heterogeneity [WMD, 0.01; 95\% confidence interval (CI), -0.01-0.03; P=0.26; Fig. 2].

Complications. Four studies reported complications of the two treatments $(19-21,23)$. Meta-analysis revealed that the complications observed were not significantly different between the antibiotic and the appendicectomy groups (OR, 0.86; 95\% CI, 0.59-1.26; $\mathrm{P}=0.50)$. In addition, there was no significant heterogeneity (Fig. 3).

Time (days) to work. Two studies reported the time (days) to work $(19,25)$. The results demonstrated that time to work was significantly longer in the appendicectomy group when 
Review: Meta-analysis of therapeutic effect of antibiotic versus appendicectomy as treatment of acute appendicitis unselected patients Comparison: 01 antibiotic versus appendicectomy as treatment of acute appendicitis Outcome: 01 Hospital stay (days)

\begin{tabular}{|c|c|c|c|c|c|c|c|}
\hline $\begin{array}{l}\text { Study } \\
\text { or sub-category }\end{array}$ & $\mathrm{N}$ & $\begin{array}{l}\text { antibiotic } \\
\text { Mean (SD) }\end{array}$ & $\mathrm{N}$ & $\begin{array}{l}\text { appendicectomy } \\
\text { Mean(SD) }\end{array}$ & $\begin{array}{l}\text { WMD(fixed) } \\
95 \% \text { CI }\end{array}$ & $\begin{array}{c}\text { Weight } \\
\%\end{array}$ & $\begin{array}{l}\text { WMD(fixed) } \\
95 \% \text { CI }\end{array}$ \\
\hline $\begin{array}{l}\text { Eriksson S } \\
\text { Gibeily GJ } \\
\text { Styrud J } \\
\text { Hansson J } \\
\text { Turhan AN }\end{array}$ & $\begin{array}{r}20 \\
17 \\
128 \\
119 \\
107\end{array}$ & $\begin{array}{l}3.10(0.10) \\
8.60(1.70) \\
3.00(1.40) \\
2.00(0.10) \\
3.14(0.10)\end{array}$ & $\begin{array}{r}20 \\
15 \\
124 \\
250 \\
183\end{array}$ & $\begin{array}{l}3.30(1.90) \\
7.80(0.90) \\
2.60(1.20) \\
3.00(0.20) \\
2.30(0.14)\end{array}$ & \multirow[t]{2}{*}{$\approx$} & $\begin{array}{r}0.06 \\
0.05 \\
0.41 \\
44.88 \\
54.61\end{array}$ & $\begin{array}{r}-0.20[-1.03,0.63] \\
0.80[-0.13,1.73] \\
0.40[0.08,0.72] \\
-1.00[-1.03,-0.97] \\
0.84[0.81,0.87]\end{array}$ \\
\hline \multicolumn{5}{|c|}{$\begin{array}{l}\text { Total }(95 \% \mathrm{CI}) \\
\text { Test for heterogeneity: Chi? }=7623.66, \mathrm{df}=4(\mathrm{P}<0.00001), \mathrm{I} ?=99.9 \% \\
\text { Test for overall effect: } \mathrm{Z}=1.13(\mathrm{P}=0.26)\end{array}$} & & 100.00 & $0.01[-0.01,0.03]$ \\
\hline
\end{tabular}

Figure 2. RCTs comparing antibiotic treatment with surgery in acute appendicitis by the time (days) of hospital stay. WMD, weighted mean difference; CI, confidence interval; RCT, randomized controlled trial.

Review: Meta-analysis of therapeutic effect of antibiotic versus appendicectomy as treatment of acute appendicitis unselected patients Comparison: 01 antibiotic versus appendicectomy as treatment of acute appendicitis Outcome: 03 Complications

\begin{tabular}{|c|c|c|c|c|c|}
\hline $\begin{array}{l}\text { Study } \\
\text { or sub-category }\end{array}$ & $\begin{array}{l}\text { antibiotic } \\
\mathrm{n} / \mathrm{N}\end{array}$ & $\begin{array}{c}\text { appendicectomy } \\
\mathrm{n} / \mathrm{N}\end{array}$ & $\begin{array}{l}\text { OR(fixed) } \\
95 \% \mathrm{CI}\end{array}$ & $\begin{array}{c}\text { Weight } \\
\%\end{array}$ & $\begin{array}{l}\text { OR(fixed) } \\
95 \% \mathrm{CI}\end{array}$ \\
\hline $\begin{array}{l}\text { Eriksson S } \\
\text { Gibeily GJ } \\
\text { Styrud J } \\
\text { Hansson J }\end{array}$ & $\begin{array}{c}0 / 20 \\
4 / 17 \\
15 / 128 \\
36 / 119\end{array}$ & $\begin{array}{c}1 / 20 \\
5 / 15 \\
17 / 124 \\
80 / 250\end{array}$ & $\longleftarrow \longrightarrow \frac{m}{\longrightarrow \rightarrow}$ & $\begin{array}{r}2.58 \\
7.16 \\
26.86 \\
63.40\end{array}$ & $\begin{array}{l}0.32[0.01,8.26] \\
0.62[0.13,2.90] \\
0.84[0.40,1.76] \\
0.92[0.57,1.48]\end{array}$ \\
\hline $\begin{array}{l}\text { Total }(95 \% \mathrm{CI}) \\
\text { Total events: } 55 \\
\text { Test for heterog } \\
\text { Test for overall }\end{array}$ & $\begin{array}{l}284 \\
3 \text { (appendic } \\
63, \mathrm{df}=3(\mathrm{P} \\
\mathrm{P}=0.44)\end{array}$ & y) $I ?=0 \%$ & & 100.00 & $0.86[0.59,1.26]$ \\
\hline
\end{tabular}

Figure 3. RCTs comparing antibiotic treatment with surgery in acute appendicitis by complications. OR, odds ration; CI, confidence interval; RCT, randomized controlled trial.

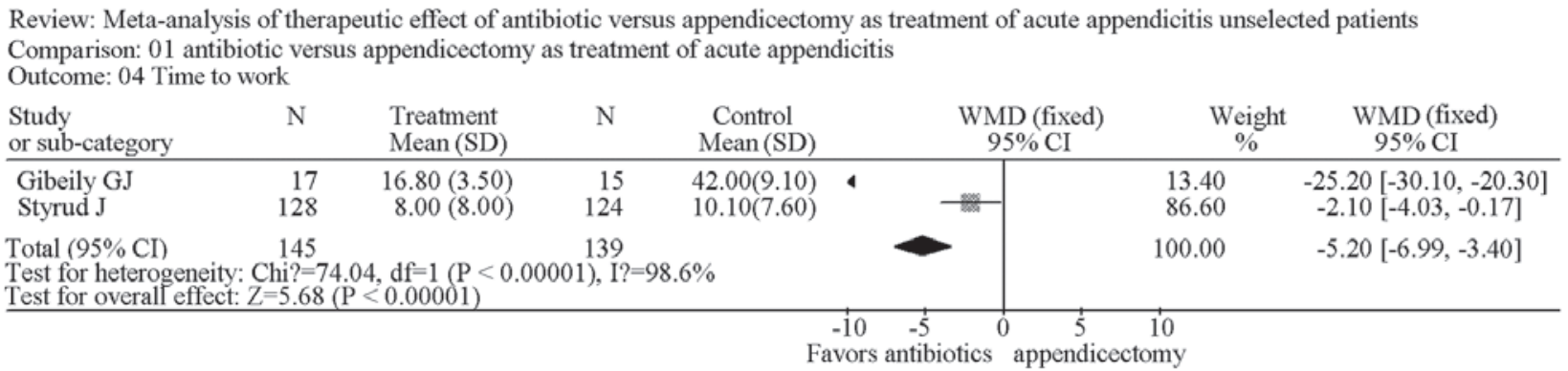

Figure 4. RCTs comparing antibiotic treatment with surgery in acute appendicitis by time (days) to work. WMD, weighted mean difference; CI, confidence interval; RCT, randomized controlled trial.

compared with the antibiotic group (WMD, $-5.20 ; 95 \% \mathrm{CI}$, -6.99--3.40; $\mathrm{P}<0.00001)$. There was no significant heterogeneity (Fig. 4).

Sensitivity analysis. Removing individual studies from the data set did not substantially change the OR and WMD values or the level of significance for the three most important clinical outcomes (time of hospital stay, time to work and complications).

Testing for publication bias. A funnel plot of the outcome of complications following treatment with antibiotics and appendicectomy in the included studies demonstrated symmetry, indicating there was no serious publication bias (Fig. 5).

\section{Discussion}

Acute appendicitis is the most common intra-abdominal condition requiring emergency surgery $(24,25)$. Appendicectomy has been regarded as the gold standard for acute appendicitis for more than a century. However, conservative treatment has been increasingly studied in selected patients during recent years. In addition, the increasing diagnostic accuracy of acute appendicitis has contributed to the use of antibiotic therapy (26-28).

The present meta-analysis evaluated the therapeutic effects of antibiotics and appendicectomy for the treatment of acute appendicitis. The meta-analysis results indicated that there was no significant difference between the antibiotic and 


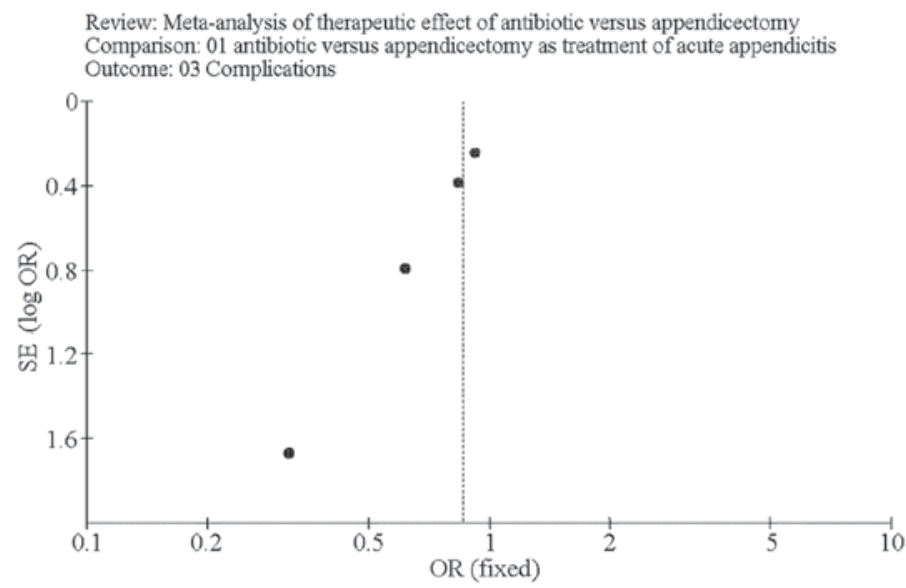

Figure 5. Funnel plot of the complications of antibiotic treatment and surgery. OR, odds ratio.

appendicectomy groups with regard to the time of hospital stay and complications. However, time to work was significantly longer in the appendicectomy group when compared with the antibiotic group.

The time of hospital stay was not significantly different between the antibiotic and appendicectomy groups. Conservative therapy has delayed effects on appendicitis compared with that of appendicectomy (29). Therefore, patients must wait for the alleviation of symptoms in hospital. However, following parenteral administration of antibiotics for only $24 \mathrm{~h}$, patients with appendicitis were discharged with oral antibiotics and had a follow-up examination 1 week after discharge, shortening the time of hospital stay (30). Therefore, the present study found that there was no significant differences between the two groups in terms of hospital stay.

There was no significant difference between the antibiotic and appendicectomy groups in terms of complications. However, major complications, including small bowel obstruction, wound rupture and postoperative cardiac problems, were mainly observed in the appendicectomy group, while minor complications, including diarrhea and fungal infection, existed primarily in the antibiotic group $(31,32)$. Therefore, antibiotic therapy is advantageous compared with appendicectomy for the treatment of acute appendicitis (33).

Time to work may be the main advantage of antibiotic treatment for acute appendicitis. Results revealed that time to work was significantly longer in the appendicectomy group when compared with the antibiotic group. This may be due to the longer recovery time required following surgery before patients were able to work (34).

There are additional advantages of antibiotic treatment versus surgery, one of which may be the overall medical cost (35). In addition, antibiotic treatment may avoid surgical complications, including small bowel obstruction and negative appendicectomy (36). Additionally, the rate of mortality is low compared with appendicectomy (37). Antibiotic treatment is also recommended in patients with a high surgical risk, particularly elderly patients with poor heart and lung function or severely obese patients, which may be a contraindication for surgery $(21,38)$.

However, disadvantages of antibiotic treatment also exist. Allergy to the therapeutic agents may withhold the application of antibiotic treatment (39). However, this problem may be avoided relatively easily if surgeons pay increased attention to the possibility of allergies and prescribe antibiotics suitable for different patients (40).

Due to the large number of patients, antibiotic abuse may also be a problem, which may enhance multiple drug resistance in bacterial strains against various antibiotics (41). However, it can be resolved by using antibiotics according to the results of bacterial culture, appropriately. Furthermore, comprehensive medical history and physical examination are necessary and the definite diagnosis may also be confirmed by imaging examination (42).

It is ineffective to analyze trials that differ in terms of underlying conditions and intervention in a meta-analysis (43). Conditions and interventions were similar in the present meta-analysis in order to increase clinical homogeneity between the trials. However, one study discriminated the patient groups as intention-to-treat and per protocol (20) and clinical variables were not mentioned. In addition, one study classified the complications as major or minor (20).

The number of patients is relatively small in numerous RCTs. In the present meta-analysis, a relatively large number of patients were included to enhance the reliability of the results. As previously mentioned, of the 983 patients in the five RCTs, 391 were allocated to the antibiotic group, while 592 comprised the appendicectomy group and the therapeutic effects of the two treatments were evaluated.

In the present study, randomization, allocation concealment and blinding assessment of outcomes were rarely performed, as only two studies were reported as double-blinded tests, due to ethical concern or practical difficulty $(20,23)$. However, this may be superior to a number of other studies, which had rare allocation concealment and blinding assessment (17). Theoretically, the absence of allocation concealment and double-blinding may have resulted in overvaluing the effects of antibiotic treatment on specific measures of postoperative recovery and other associated indexes (44). However, Bruix et al reported that individual quality measures, including blinding and allocation concealment, are not reliably associated with the strength of treatment effects in meta-analyses of RCTs (45).

In conclusion, the present meta-analysis indicated that acute appendicitis may be treated successfully with antibi- 
otics. In addition, the therapeutic effects of antibiotics and appendicectomy were comparable for the treatment of acute appendicitis. Therefore, we recommend that more individuals are considered for antibiotic therapy instead of surgery.

\section{Acknowledgements}

This study was supported by a grant from the National Natural Science Foundation of China (no. 81070293).

\section{References}

1. Humes DJ and Simpson J: Acute appendicitis. BMJ 333: 530-534, 2006.

2. Howie JG: Acute appendicitis: acute appendicitis or acute appendicectomy? BMJ 333: 653, 2006.

3. Fitz RH: Perforating inflammation of the vermiform appendix: with special reference to its early diagnosis and treatment. Am J Med Sci 92: 321-346, 1886.

4. Andersson RE and Petzold MG: Nonsurgical treatment of appendiceal abscess or phlegmon: a systematic review and meta-analysis. Ann Surg 246: 741-748, 2007.

5. Choudhary RK and Hassn AM: Managing acute appendicitis. Neuroimmune appendicitis may be distinct pathological entity. BMJ 326: 49, 2003

6. Coldrey E: Five years of conservative treatment of acute appendicitis. J Int Coll Surg. 32: 255-261, 1959.

7. No authors listed: Combined traditional Chinese and Western medicine in acute appendicitis. Chin Med J (Engl) 3: 266-269, 1977.

8. Varadhan KK, Humes DJ, Neal KR and Lobo DN: Antibiotic therapy versus appendectomy for acute appendicitis: a meta-analysis. World J Surg 34: 199-209, 2010.

9. Vons C: Can acute appendicitis be treated by antibiotics and in what conditions? J Chir (Paris) 146: 17-21, 2009 (In French).

10. Liu K, Ahanchi S, Pisaneschi M, Lin I and Walter R: Can acute appendicitis be treated by antibiotics alone? Am Surg 73: 1161-1165, 2007

11. Levin T, Whyte C, Borzykowski R, Han B, Blitman N and Harris B: Nonoperative management of perforated appendicitis in children: can CT predict outcome? Pediatr Radiol 37: 251-255, 2007.

12. Aprahamian CJ, Barnhart DC, Bledsoe SE, Vaid Y and Harmon CM: Failure in the nonoperative management of pediatric ruptured appendicitis: predictors and consequences. J Pediatr Surg 42: 934-938, 2007.

13. Abeş M, Petik B and Kazil S: Nonoperative treatment of acute appendicitis in children. J Pediatr Surg 42: 1439-1442, 2007.

14. Dixon MR, Haukoos JS, Park IU, et al: An assessment of the severity of recurrent appendicitis. Am J Surg 186: 718-722, 2003.

15. Wilson DG, Bond AK, Ladwa N, Sajid MS, Baig MK and Sains P: Intra-abdominal collections following laparoscopic versus open appendicectomy: an experience of 516 consecutive cases at a district general hospital. Surg Endosc 27: 2351-2356, 2013.

16. Varadhan KK, Neal KR and Lobo DN: Safety and efficacy of antibiotics compared with appendicectomy for treatment of uncomplicated acute appendicitis: meta-analysis of randomised controlled trials. BMJ 344: e2156, 2012.

17. Yang Z, Zheng Q and Wang Z: Meta-analysis of the need for nasogastric or nasojejunal decompression after gastrectomy for gastric cancer. Br J Surg 95: 809-816, 2008.

18. Moher D, Pham B, Jones A, et al: Does quality of reports of randomised trials affect estimates of intervention efficacy reported in meta-analyses? Lancet 352: 609-613, 1998.

19. Gibeily GJ, Ross MN, Manning DB, Wherry DC and Kao TC: Late-presenting appendicitis: a laparoscopic approach to a complicated problem. Surg Endosc 17: 725-729, 2003.

20. Hansson J, Körner U, Khorram-Manesh A, Solberg A and Lundholm K: Randomized clinical trial of antibiotic therapy versus appendicectomy as primary treatment of acute appendicitis in unselected patients. Br J Surg 96: 473-481, 2009.

21. Styrud J, Eriksson S, Nilsson I, et al: Appendectomy versus antibiotic treatment in acute appendicitis. A prospective multicenter randomized controlled trial. World J Surg 30: 1033-1037, 2006.
22. Turhan AN, Kapan S, Kütükçü E, Yiğitbaş H, Hatipoğlu S and Aygün E: Comparison of operative and non operative management of acute appendicitis. Ulus Travma Acil Cerrahi Derg 15: 459-462, 2009.

23. Eriksson S and Granström L: Randomized controlled trial of appendicectomy versus antibiotic therapy for acute appendicitis. Br J Surg 82: 166-169, 1995.

24. Gutt CN, Müller-Stich BP and Reiter MA: Success and complication parameters for laparoscopic surgery: a benchmark for natural orifice transluminal endoscopic surgery. Endoscopy 41: 36-41, 2009.

25. Boni L, Dionigi G, Rovera F and Di Giuseppe M: Laparoscopic left liver sectoriectomy of Caroli's disease limited to segment II and III. J Vis Exp 24: 1118, 2009.

26. Binnebösel M, Otto J, Stumpf M, et al: Acute appendicitis. Modern diagnostics - surgical ultrasound. Chirurg 80: 579-587, 2009 (In German).

27. Cavuşoğlu YH, Erdoğan D, Karaman A, Aslan MK, Karaman I and Tütün OC: Do not rush into operating and just observe actively if you are not sure about the diagnosis of appendicitis. Pediatr Surg Int 25: 277-282, 2009.

28. Tzanakis NE, Efstathiou SP, Danulidis K, et al: A new approach to accurate diagnosis of acute appendicitis. World J Surg 29: 1151-1156, 2005.

29. Christiansen SE, Jakobsen BW, Lund B and Lind M: Isolated repair of the medial patellofemoral ligament in primary dislocation of the patella: a prospective randomized study. Arthroscopy 24: 881-887, 2008.

30. Malik AA and Bari SU: Conservative management of acute appendicitis. J Gastrointest Surg 13: 966-970, 2009.

31. Lemieux P, Rheaume P, Levesque I, Bujold E and Brochu G: Laparoscopic appendectomy in pregnant patients: a review of 45 cases. Surg Endosc 23: 1701-1705, 2009.

32. Kamiński J,Zielińska-Leś I and Kozielski J: Invasive pulmonary aspergillosis as a complication of prolonged antibiotic therapy. Pol Merkur Lekarski 18: 700-702, 2005 (In Polish).

33. Matthaiou DK, Peppas G and Falagas ME: Meta-analysis on surgical infections. Infect Dis Clin North Am 23: 405-430, 2009.

34. Wei HB, Huang JL, Zheng ZH, et al: Laparoscopic versus open appendectomy: a prospective randomized comparison. Surg Endosc 24: 266-269, 2010.

35. Edelsberg J, Berger A, Schell S, Mallick R, Kuznik A and Oster G: Economic consequences of failure of initial antibiotic therapy in hospitalized adults with complicated intra-abdominal infections. Surg Infect (Larchmt) 9: 335-347, 2008.

36. Partelli S, Beg S, Brown J, Vyas S and Kocher HM: Alteration in emergency theatre prioritisation does not alter outcome for acute appendicitis: comparative cohort study. World J Emerg Surg 4: 22, 2009.

37. Wong SL, Anthony EY and Shetty AK: Pyomyositis due to Streptococcus pneumoniae. Am J Emerg Med 27: 633, 2009.

38. Barbour A, Schmidt S, Rout WR, Ben-David K, Burkhardt O and Derendorf H: Soft tissue penetration of cefuroxime determined by clinical microdialysis in morbidly obese patients undergoing abdominal surgery. Int J Antimicrob Agents 34: 231-235, 2009.

39. Carson HJ and Cook BA: Mast cell tryptase in a case of anaphylaxis due to repeat antibiotic exposure. Leg Med (Tokyo) 11: 234-236, 2009.

40. La Shell MS and Tankersley MS: Antibiotics for the allergist: part 2. Ann Allergy Asthma Immunol 102: 1-7, 2009.

41. Hellmark B, Unemo M, Nilsdotter-Augustinsson A and Söderquist B: Antibiotic susceptibility among Staphylococcus epidermidis isolated from prosthetic joint infections with special focus on rifampicin and variability of the rpoB gene. Clin Microbiol Infect 15: 238-244, 2009.

42. Metzger R, Bonatti H and Sawyer R: Future trends in the treatment of serious Gram-positive infections. Drugs Today (Barc) 45: 33-45, 2009.

43. Hogle NJ, Chang L, Strong VE, et al: Validation of laparoscopic surgical skills training outside the operating room: a long road. Surg Endosc 23: 1476-1482, 2009.

44. Suenaga M, Sugiura H, Kokuba Y, Uehara S and Kurumiya T: Repeated hepatic resection for recurrent hepatocellular carcinoma in eighteen cases. Surgery 115: 452-457, 1994.

45. Bruix J, Sherman M, Llovet JM, et al: Clinical management of hepatocellular carcinoma. Conclusions of the Barcelona-2000 EASL conference. European Association for the Study of the Liver. J Hepatol 35: 421-430, 2001. 